\title{
Perceptions of Risk Factors for Road Traffic Accidents
}

\author{
Andrew Smith \\ Centre for Occupational \& Health Psychology \\ School of Psychology, Cardiff University \\ Hugo Smith \\ Centre for Occupational \& Health Psychology \\ School of Psychology, Cardiff University
}

\begin{abstract}
Research has identified a number of risk factors for road traffic accidents. Some of these require education of drivers and a first step in this process is to assess perceptions of these risk factors to determine the current level of awareness. An online survey examined risk perception with the focus being on driver behavior, risk taking and fatigue. The results showed that drivers' perceptions of the risk from being fatigued was lower than the perceived risk from the other factors.
\end{abstract}

Keywords: road traffic accidents; driving behaviour; risk taking; fatigue

\section{RISK FACTORS FOR ROAD TRAFFIC ACCIDENTS}

Road traffic accidents (RTAs) are a major cause of injury, mortality and financial cost [1]. There has been extensive research on RTAs and it is apparent that human error is often involved. Driver fatigue has been shown to be involved in $15-30 \%$ of all crashes $[2,3,4,5]$. Legislation aims to prevent some risks (e.g. effects of alcohol or drugs) and bad driving behaviour, such as speeding, often incurs sanctions and/or compulsory attendance of appropriate training courses [6]. Other issues, such as fatigue, are often included in courses for professional drivers [7] and publicity campaigns aimed at non-commercial drivers (e.g. the Think! campaign).

A recent study [8] investigated the extent to which poor driving behaviour, driving when fatigued and risk taking were risk factors for RTAs. Driver behaviour is usually assessed by questionnaire $[9,10]$ and the main types of problem that have been identified are speeding, lapses of attention, errors and aggressive driving. Risk taking is a general type of behaviour which has a major impact in safety critical contexts such as driving. Much of the research on driver fatigue has focused on the length of time spent driving [11]. However, fatigue may be due to many factors, some of which may be present at the start of the drive rather than actual time driving. There is evidence that driving impairments are related to time of day [4], loss of sleep or sleep inertia [12], prolonged work [13] and minor illness [14]. It is important, therefore, to assess the frequency with which people drive when they are potentially fatigued because of this range of risk factors. The study involved an online survey of nearly 3000 clients of an insurance company. Job characteristics, psychosocial factors, demographic and lifestyle factors were also recorded and adjusted for in the statistical analyses. Factor analyses showed that driving when fatigued, risk taking and driving behaviour were independent factors. Logistic regressions revealed that frequently driving when fatigued, taking risks and poor driving behaviour predicted RTAs. These effects were additive and those who reported all of the risk factors were twice as likely to have an RTA. These effects were still significant when 
work, psychosocial, demographic, lifestyle, medical, and driving (e.g. annual mileage) factors were included in the analyses. Smith [8] concluded that education programmes must now be used to increase awareness of these risk factors.

As a starting point for these education programmes an online survey was conducted to determine the level of awareness of these risk factors in drivers differing in age, gender, driving experience, miles driven and whether they had been involved in an RTA. The risk factors studied by [8] were embedded in a list of potential risk factors, some of which have strong evidence (e.g. effects of alcohol) and others little evidence (e.g. driving with the window open).

\section{The survey}

\section{METHOD}

The survey was carried out with approval of the ethics committee, School of Psychology, Cardiff University and with the informed consent of the volunteers. The survey was sent to participants who were members of the Qualtrics research panel using an online survey. The survey collected information on demographics, annual mileage, driving experience and prior involvement in an RTA (see Table 1). It then included potential hazards (see Table 2) and participants had to rate their perceived risk on a 10-point scale (from "Not at all" to "Very much so").

\section{The sample}

210 drivers took part in the survey, with an even split of male and female participants. The frequencies of drivers in age categories are shown below. Information was also taken on the participant's number of years they had been driving and the miles driven per year, also shown below. 


$\begin{array}{lc}\text { Table 1. Characteristics of the sample } \\ \text { Age (years) } & \text { N (\%) } \\ 17-20 & 5(2.4) \\ 21-30 & 35(16.7) \\ 31-40 & 39(18.6) \\ 41-50 & 64(30.5) \\ 51-60 & 31(14.8) \\ 61-70 & 36(17.1) \\ & \\ \text { Years driving } & \mathbf{N}(\%) \\ <1 & 6(2.9) \\ 1-3 & 9(4.3) \\ 4-10 & 32(15.2) \\ 10-20 & 44(21) \\ 20-30 & 49(23.3) \\ >30 & 70(33.3) \\ & \\ \text { Annual mileage } & \mathbf{N}(\%) \\ <1000 & 11(5.2) \\ 1000-2000 & 13(6.2) \\ 2000-3000 & 18(8.6) \\ 3000-4000 & 28(13.3) \\ 4000-5000 & 28(13.3) \\ 5000-10000 & 68(32.4) \\ >10000 & 44(21) \\ \end{array}$

$32.8 \%$ acknowledged they had been in a traffic accident without suffering a serious injury, while only $7.4 \%$ had been in a tr affic accident that had resulted in the driver suffering an injury

\section{Descriptive statistics}

\section{RESULTS}

The table below is a ranking of the hazards that people identified as a serious risk when driving. A serious risk score was defined as a score of ' 9 ' or ' 10 '. 
Table 2. Perceived risks of potential hazards

\begin{tabular}{|c|c|c|c|}
\hline Hazard & 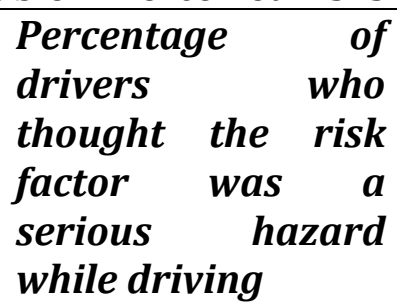 & $\begin{array}{lr}\text { Percentage } & \text { of } \\
\text { drivers } & \text { who } \\
\text { rated } & \text { the } \\
\text { hazard }>7 / 10\end{array}$ & $\begin{array}{l}\text { Mean response } \\
\text { score across the } \\
\text { survey }\end{array}$ \\
\hline $\begin{array}{l}\text { Driving after } \\
\text { drinking four units of } \\
\text { alcohol }\end{array}$ & $66.2 \%$ & $79.5 \%$ & 8.40 \\
\hline $\begin{array}{l}\text { Taking risks while } \\
\text { driving }\end{array}$ & $62.4 \%$ & $78.6 \%$ & 8.39 \\
\hline $\begin{array}{l}\text { Having lapses of } \\
\text { concentration whilst } \\
\text { driving }\end{array}$ & $50.5 \%$ & $73.8 \%$ & 8.06 \\
\hline Driving when tired & $48.5 \%$ & $72.8 \%$ & 8.19 \\
\hline $\begin{array}{l}\text { Frequently missing } \\
\text { warning signs }\end{array}$ & $42.9 \%$ & $63.9 \%$ & 7.70 \\
\hline $\begin{array}{l}\text { Disregarding the } \\
\text { speed limit on a } \\
\text { residential road }\end{array}$ & $41.9 \%$ & $62.9 \%$ & 7.64 \\
\hline $\begin{array}{l}\text { Indicating hostility to } \\
\text { other drivers }\end{array}$ & $27.2 \%$ & $42.4 \%$ & 7.09 \\
\hline $\begin{array}{lll}\begin{array}{l}\text { Driving } \\
\text { periods }\end{array} & \text { for long } \\
\end{array}$ & $23.8 \%$ & $42.8 \%$ & 7.12 \\
\hline $\begin{array}{l}\text { Driving when feeling } \\
\text { stressed }\end{array}$ & $22.9 \%$ & $44.3 \%$ & 6.98 \\
\hline $\begin{array}{l}\text { Driving in bad } \\
\text { weather }\end{array}$ & $17.1 \%$ & $43.8 \%$ & 7.13 \\
\hline $\begin{array}{l}\text { Driving after } \\
\text { prolonged work }\end{array}$ & $13.8 \%$ & $30 \%$ & 6.50 \\
\hline $\begin{array}{l}\text { Driving late at night, } \\
\text { early in the morning } \\
\text { or post-lunch }\end{array}$ & $11 \%$ & $22.9 \%$ & 5.70 \\
\hline $\begin{array}{l}\text { Driving with the } \\
\text { radio on }\end{array}$ & $5.7 \%$ & $11.9 \%$ & 4.36 \\
\hline $\begin{array}{l}\text { Driving when you } \\
\text { have a minor illness }\end{array}$ & $4.8 \%$ & $11.5 \%$ & 4.71 \\
\hline $\begin{array}{l}\text { Driving on a route } \\
\text { you do not know }\end{array}$ & $4.3 \%$ & $18.1 \%$ & 5.69 \\
\hline $\begin{array}{l}\text { Driving with a } \\
\text { passenger }\end{array}$ & $2.9 \%$ & $8.1 \%$ & 4.05 \\
\hline $\begin{array}{l}\text { Driving after going to } \\
\text { the gym }\end{array}$ & $2.8 \%$ & $9 \%$ & 4.14 \\
\hline $\begin{array}{l}\text { Driving with the } \\
\text { window open }\end{array}$ & $2 \%$ & $6.8 \%$ & 3.30 \\
\hline
\end{tabular}




\section{Factor Analysis}

Factor analysis of the potential risk factors revealed a two factor solution representing high and low perceived risk. Each variable loading on a factor and its weighting is shown below:

\section{Perceived high risks}

Risk taking (.921), tired (.872), missing warning signs (.858), lapses of concentration (.843), disregarding the speed limit on a residential road (.817), alcohol (.816), hostility (.711), stressed (.637) and long periods of driving (.566).

\section{Perceived low risks}

Window open (.817), gym (.801), late at night, early morning or post-lunch (.771), radio (.764), minor illness (.762), unknown route (.710), prolonged work (.614) and driving with a passenger (.609).

\section{Gender}

\section{INDIVIDUAL DIFFERENCES}

T-tests were used to identify if there were significant differences between the two sexes. The tests revealed that the scores for both genders were generally very similar. Some exceptions were that the female group believed that driving with a passenger, in bad weather, whilst stressed and driving after a prolonged period of work were more dangerous than the male group.

\section{Age}

One-way ANOVA tests were carried to compare the different age groups. Post-hoc comparisons were then performed to determine where any differences occurred. There were six age groups tested across the survey, from 17-20 up to 61-70. There were significant differences between the 21-30 and the 31-40 groups compared to the 61-70 when it came to driving with a passenger, with the latter group thinking that driving with a passenger was much less of a hazard than the other two groups. Perhaps the most significant group difference was the difference between the 31-40 group and rest when it came down to the more serious perceived driving hazards. The 31-40 group thought that taking risks when driving (the mean score for the 31-40 was 7.36, while ever other age group exceeded 8.40) and driving after drinking four units of alcohol were less serious risks than did all the other groups (the mean score for the 3140 was 6.92, while ever other age group exceeded 8.30). Additionally, the 31-40 group did not feel that frequently missing warning signs was as much as an issue as the rest of the groups, particularly the 61-70 and 21-30 groups.

\section{Previous traffic accidents no injury}

Drivers who had not had a traffic accident rated the hazards perceived as low risk (such as driving with the window open, driving with the radio on and driving after going to the gym) as a bigger potential risk than those in the accident group.

\section{Driver traffic accidents resulting in injury}

Drivers who had suffered an injury in a driving accident felt that driving with a passenger and driving in bad weather were much more significant risks than those who had no accident.

\section{Annual mileage and years driving}

One-way ANOVA tests revealed that there were no significant effects of driving experience or miles driven per year on perception of risks. 


\section{DISCUSSION}

The results from this survey confirmed that the more established risk factors (e.g. driving after consuming alcohol; driving when tired) were rated as a greater risk than some factors which have only recently been identified (e.g. driving when having a cold - [14]. It is interesting that even the more well-established risk factors were not perceived as high risk by some groups (e.g. the 31-40 year age group and the risk from alcohol consumption). This suggests that further education is required even for these well-established risks. If one returns to the results from [8] which led to the study, risk taking and inappropriate driving behaviour loaded in the high-risk category. Those potential hazards which were shown to be related to RTAs but here were perceived as low risk were: driving late at night, in the early morning or after lunch (i.e. when circadian alertness is low), driving after prolonged work and driving with a minor illness. Further education is clearly required about these potential risks and also the combination of factors. For example, the risk of having an RTA is increased in those returning home after a 12hour nightshift (the combination of prolonged work and working at time when one would normally sleep). It would have been useful to have seen the risk ratings for specific scenarios rather than general issues and it may be that education based on these is going to be an important strategy. It is also the case that the impact of fundamental research takes time to be disseminated. Some of the research on the fatigue related hazards has only recently been published [14, 8] and dissemination is clearly required to increase awareness of these studies. Dissemination should take several forms (e.g. film media; driver training courses; and press coverage) and should be promoted by all stakeholders concerned with safe driving (e.g. the WHO, the Department of Transport; the insurance industry; safety-promoting organisations; and motoring organisations who encourage safe driving). A driving fatigue campaign should be more holistic and address fatigue induced by factors other than time driving. Many of these points may seem obvious but they are not part of current recommendations for safer driving [15].

The present study has a several limitations; it used a small sample and a very brief survey. An advantage of this short measuring instrument is that it could be used as a method of quickly auditing the impact of interventions aimed at informing drivers about potential risks. In conclusion, it is important to have information about perceptions of risk factors for RTAs and the present study demonstrated how such data can be easily collected. The results showed that recently identified risk factors, especially those relating to fatigue when the person starts to drive, are perceived as having a lower risk than the more established ones. This suggests further dissemination of the research findings and that a variety of different methods need to be used to communicate this knowledge.

\section{References}

1. World Health Organization (2013). Global status report on road safety supporting a decade of action. Geneva.

2. Anund A., Ihlstrom J., Fors C, Kecklund G., \& Filtness A. (2016). Factors associated with self-reported driver sleepiness and incidents in city bus drivers. Ind Health 54, 337-346.

3. Connor J., Norton R., Ameuratunga S., Robinson E., Civil I., Dunn R., Bailey J., \& Jackson R. (2002). Driver sleepiness and risk of serious injury to car occupants: population based case control study. Br. Med. J. 324, 1125.

4. Horne J. \& Reyner L. (1995). Sleep related vehicle accidents. Br. Med. J., 310, 565-567.

5. Klauer S.., Dingus T., Neale V., Sudweeks J., \& Ramsey D. (2006). The impact of driver inattention on nearcrash/crash risk: An analysis using the 100-car naturalistic driving study data. Washington DC: NHTSA. Technical Report DOT HS 810594. 
6. Speed awareness course: http://www.theaa.com/aadrivetech/driver-awareness/speed-awarenesscourse.html

7. Taylor AH. \& Dorn L. (2006). Stress., fatigue., health., and risk of road traffic accidents among professional drivers. Annu. Rev. Public Health, 27, 371-91.

8. Smith (2016). A UK survey of driving behaviour, fatigue, risk taking and road traffic accidents. BMJ Open 6:e011461. doi:10.1136/bmjopen-2016-011461.

9. Reason J., Manstead A., Stradling S., Baxter J., Campbell K. (1990). Errors and violations on the road: a real distinction? Ergonomics, 33:1315-1332.

10. Parker D., West DR., Stradling S., \& Manstead AS. (1995). Behavioural characteristics and involvement in different types of traffic accident. Accid Anal Prev, 27, 571-81.

11. Quera Salva MA., Barbot F., Hartley S., Sauvagnac R., Vaugier I., Lofaso F., \& Philip, P. (2014). Sleep disorders., sleepiness., and near-miss accidents among long-distance highway drivers in the summertime. Sleep Med 2014, 15(1):23-6.

12. Philip P., Chaufton C., Orriols L., Lagarde E., Amoros E., Laumon B., Akerstedt T., Taillard J., \& Sagaspe P. (2014). Complaints of Poor Sleep and Risk of Traffic Accidents: A Population-Based Case-Control Study. PLoS One, 9(12):e114102.

13. Valent F., Di Bartolomeo S., Marchetti R., Sbrojavacca R., \& Barbone F. (2010). A case-crossover study of sleep and work hours and the risk of road traffic accidents. Sleep, 33(3), 349-54.

14. Smith AP., Jamson SL. (2012). An investigation of the effects of the common cold on simulated driving performance and detection of collisions. BMJ Open, 2, e001047.

15. Mohan D., Tiwari G., Khayesi M., \& Nafukho FM. (2007). Road traffic injury prevention training manual. WHO: Indian Institute of Technology Delhi. 